\title{
EDUCAÇÃO PARA A LEITURA CRÍTICA DA MÍDIA, DEMOCRACIA RADICAL E A RECONSTRUÇÃO DA EDUCAÇÃO*
}

\author{
DOUglas KeLLner ${ }^{* *}$ \\ JeFF SHARE**
}

\begin{abstract}
RESUMO: Neste artigo, exploram-se as bases teóricas da educação para a leitura crítica da mídia e analisam-se diferentes abordagens a serem empregadas em seu ensino. Ao combinar estudos culturais com pedagogia crítica, defendemos uma discussão em defesa da alfabetização crítica da mídia, que vise a ampliar a noção de alfabetização, incluindo uma ampla variedade de formas de cultura midiática, informações e tecnologias da comunicação e novos meios de comunicação, além de aprofundar o potencial da alfabetização para analisar criticamente relações entre os meios de comunicação e as audiências, a informação e o poder. Utiliza-se uma abordagem multiperspectivista, tratando de questôes de gênero, raça, classe e poder, para explorar as inter-relaçôes entre a alfabetização midiática, os estudos culturais e a pedagogia crítica. Nossa versão de alfabetização digital integra análise e produção e visa a dar poderes aos alunos para que tenham plena participação em sua sociedade. Assim, essa visão promove a democracia radical e a justiça social.
\end{abstract}

Palavras-chave: Alfabetização midiática. Alfabetização crítica da mídia. Educação midiática. Pedagogia crítica. Estudos culturais. Democracia radical.

* Tradução de Márcia Barroso, com revisão técnica de Antonio Zuin.

** Catedrático de Filosofia da Educação, Ciências Sociais e Educação Comparada, da Universidade da Califórnia (Los Angeles, EUA). E-mail: kellner@ucla.edu

*** Conselheiro do Programa de Formação de Professores da Universidade da Califórnia. E-mail: jshare@ucla.edu

Educ. Soc., Campinas, vol. 29, n. 104 - Especial, p. 687-715, out. 2008 
Educação para a leitura crítica da mídia...

\title{
CRITICAL MEDIA EDUCATION, RADICAL DEMOCRACY AND THE RECONSTRUCTION OF EDUCATION
}

\begin{abstract}
This article explores the theoretical underpinnings of critical media education and analyzes contrasting approaches to teaching it. Combining cultural studies with critical pedagogy, we argue for a critical media literacy that aims to expand the notion of literacy to include a wide range of forms of media culture, information and communication technologies and new media, as well as deepen the potential of literacy education to critically analyze relationships between media and audiences, information and power. A multiperspectivist approach addressing issues of gender, race, class and power is used to explore the interconnections of media literacy, cultural studies and critical pedagogy. Our version of critical media literacy integrates analysis with production and aims at empowering students to participate fully in their society and thus promotes radical democracy and social justice.
\end{abstract}

Key words: Media literacy. Critical media literacy. Media education. Critical pedagogy. Cultural studies. Radical democracy.

\section{Educação crítica da mídia e democracia radical}

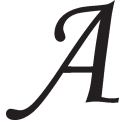

$s$ inovações tecnológicas, a expansão dos impérios globais da mídia, uma explosão de novos tipos de mídia e um ilimitado bombardeio comercial a crianças têm contribuído, atualmente, para a formação de um ambiente em que a juventude está crescendo num mundo mediado, muito diferente do de qualquer geração anterior. Se, por um lado, os avanços tecnológicos criaram novas possibilidades para o livre fluxo de informaçôes, o uso de redes sociais e o ativismo global, por outro lado, há também o potencial que as empresas e governos exercem de ampliar seu controle sobre os meios de comunicação, restringir o fluxo de informações e apropriar-se dessas novas ferramentas para o seu próprio lucro e controle, à custa da livre expressão e da democracia.

A maioria das crianças nascidas nos Estados Unidos neste milênio nunca conheceu uma época sem a internet, os telefones celulares e a televisão. ${ }^{1}$ Mais de $98 \%$ dos lares norte-americanos têm pelo menos um aparelho de televisão ${ }^{2}$ e cerca de um terço das crianças pequenas 
vive em lares em que a TV está ligada "sempre" ou "a maior parte do tempo" (Rideout, Vandewater \& Wartella, 2003, p. 4). Antes de completar seis anos de idade, a maioria das crianças passa cerca de duas horas por dia em contato com mídia na tela. ${ }^{3}$ Isso dobra aos oito anos e, antes de completarem 18 anos, elas passam aproximadamente seis horas e meia, diariamente, com todos os tipos de mídia (Rideout, Roberts \& Foehr, 2005). ${ }^{4}$ Também se estima que quase todas as crianças pequenas nos EUA "têm produtos - roupas, brinquedos e afins baseados em personagens dos programas de TV ou de cinema" (Rideout et al., 2003, p. 4). Uma vez que os programas de televisão, os videogames, a música e mesmo os brinquedos se tornaram grandes transmissores da nossa cultura, os contadores e vendedores das histórias do nosso tempo, é agora, mais do que nunca, que as crianças precisam aprender a questionar criticamente as mensagens que as cercam e usar a grande variedade de ferramentas disponíveis para expressar suas idéias e exercer plena participação na sociedade.

Victoria Carrington (2005, p. 22) escreve que o advento de textos em novos tipos de mídia "coloca as crianças em fluxos globais de consumo, identidade e informações, de uma maneira jamais vista em gerações anteriores (...)". Para Carrington, é essencial entender a mídia como um fluxo no qual os jovens de hoje estão crescendo. Tania Modleski (1982) descreve o conceito de fluxo de Raymond Williams como as complexas interações e inter-relações entre vários programas e comerciais de televisão. Beverle Houston (1984, p. 82) explica: "O fluxo da televisão americana é contínuo, vinte e quatro horas por dia, o que é crucial para produzir a idéia de que o texto sai de um estoque infinito, de origem inexistente, natural, inesgotável e concomitante com a própria realidade psicológica”. No século XXI, esse fluxo se move entre os velhos meios de comunicação e as novas tecnologias. Houston afirma que o fluxo da mídia mobiliza o desejo e o consumo, no sentido em que as interrupções estruturadas intensificam o desejo pelo consumo ilimitado.

No contexto da contínua expansão da transformação tecnológica e econômica, a alfabetização crítica da mídia é um imperativo para a democracia participativa, pois as novas tecnologias de informação e comunicação, associadas a uma cultura de mídia com base no mercado, fragmentaram, conectaram, convergiram, diversificaram, homogeneizaram, 
Educação para a leitura crítica da mídia...

estabilizaram, ampliaram e remodelaram o mundo. Essas mudanças estão reconstruindo a maneira como as pessoas pensam e reestruturando as sociedades, nos níveis local e global (Castells, 2004; Jenkins, 2006).

Enquanto a educação na mídia evoluiu a partir de muitas disciplinas, um importante campo de trabalho teórico para a alfabetização crítica da mídia surgiu do campo multidisciplinar dos estudos culturais. É um campo de questionamento crítico que teve início há mais de um século, na Europa, e continua a crescer com novas críticas da mídia e da sociedade. Dos anos de 1930 aos anos de 1960, pesquisadores do Instituto de Frankfurt para Pesquisas Sociais (Frankfurt Institute for Social Research) usaram a teoria crítica social para analisar como a cultura popular e as novas ferramentas da tecnologia da comunicação induzem à ideologia e ao controle social. Nos anos 60, pesquisadores do Centro para Estudos Culturais Contemporâneos (Centre for Contemporary Cultural Studies), da Universidade de Birmingham, trouxeram acréscimos às questôes já discutidas sobre ideologia, com uma compreensão mais sofisticada da audiência como construtores ativos de significado e não simples espelhos da realidade externa. Ao aplicaremse conceitos de semiótica, feminismo, multiculturalismo e pós-modernismo, evoluiu na mídia uma compreensão dialética de economia política, de análise textual e de teoria da audiência. A cultura popular pode ser analisada como um conjunto de forças dinâmicas que reproduzem ideologias dominantes, além de entreter, educar e oferecer as possibilidades para alternativas anti-hegemônicas (Kellner, 1995).

A educação midiática que evoluiu a partir de estudos culturais se define não tanto como um bloco específico de conhecimento ou um conjunto de habilidades; define-se mais como uma estrutura de compreensóes conceituais (Buckingham, 2003). Muitas pessoas e organizações no mundo todo já geraram suas próprias listas de conceitos ${ }^{5}$ que variam em números e formas de expressão, mas, em geral, todas tendem a coincidir em pelo menos cinco elementos básicos: 1) o reconhecimento da construção da mídia e da comunicação como um processo social, em oposição a aceitar textos como transmissores isolados de informações, neutros ou transparentes; 2) algum tipo de análise textual que explore as linguagens, gêneros, códigos e convenções do texto; 3) uma exploração do papel das audiências na negociação de significados; 4) a problematização do processo da representação para revelar e colocar em discussão questóes de ideologia, poder e prazer; 5) a análise da 
produção, das instituições e da economia política que motivam e estruturam as indústrias de mídia como negócios corporativos em busca de lucro (Kellner \& Share, 2005).

A alfabetização crítica da mídia é uma resposta educacional que amplia a noção de alfabetização, incluindo diferentes formas de comunicação de massa, cultura popular e novas tecnologias. Ela também aprofunda o potencial da alfabetização para analisar criticamente relações entre a mídia e as audiências, informação e poder. Com essa análise corrente, a produção de mídia alternativa dá aos alunos o poder de criar suas próprias mensagens, que podem desafiar textos e narrativas de mídia.

Este artigo explora as bases da educação para a leitura crítica da mídia, examina alguns dos obstáculos à implementação de mudanças pedagógicas progressistas e fornece exemplos de aplicação prática. Utiliza-se uma abordagem multiperspectivista que trata de questóes de gênero, raça, classe e poder, para explorar as interconexões entre educação midiática, estudos culturais e pedagogia crítica.

\section{Um mundo em transformação}

Muitas mudanças nas últimas décadas contribuíram largamente para a necessidade da educação para a leitura crítica da mídia. Faz-se necessária uma nova estrutura epistemológica para a alfabetização crítica da mídia, devido ao rápido desenvolvimento da tecnologia da informação e da comunicação, à expansão do capitalismo global de livre mercado e à escalada e decréscimo da diversidade lingüística cultural, que está mudando ambientes sociais em níveis local e global.

Observando o impacto da globalização sobre a identidade, Castells (2004) afirma que as vidas das pessoas estão sendo moldadas pelas forças da sociedade em rede. Ele sugere que as interconexóes entre a tecnologia, a economia, a cultura e a identidade estão desafiando, combatendo e impactando umas às outras em escala global.

Já nos anos de 1960, Marshall McLuhan argumentou que muitas das características da cultura oral pré-moderna teriam sua importância renovada à medida que a instantânea e contínua era eletrônica se mostrasse mais semelhante às culturas orais do passado remoto do que os últimos cinco séculos de alfabetização tipográfica. Ele escreveu 
Educação para a leitura crítica da mídia...

essas idéias antes da existência dos telefones celulares, da internet e da HDTV e, no entanto, hoje em dia, à medida que a World Wide Web e as comunicações sem fio se tornam lugar comum na maioria dos países do "primeiro mundo" e em muitas partes do "mundo em desenvolvimento", suas palavras soam mais verdadeiras do que quando ele as escreveu, meio século atrás.

Segundo McLuhan (1964), antes da alfabetização por via impressa, os humanos eram caçadores e colhedores, vivendo em sociedades orais com culturas tribais que eram unificadas, inclusivas, auditivas, orgânicas, e tinham altos níveis de participação. Com a invenção do alfabeto fonético, iniciou-se uma nova era. A alfabetização fazia com que o olho substituísse o ouvido e a cultura cósmica ficou fragmentada e separada por um novo sistema de repetitividade e uniformidade. No século XV, essas mudanças explodiram com a invenção da prensa de Gutenberg e, conseqüentemente, da imprensa. McLuhan chama esse período de "era mecânica" e atribui a chegada do individualismo, do racionalismo e do nacionalismo a essa nova cultura alfabetizada da homogeneidade e da organização linear.

A próxima grande mudança para a humanidade, segundo McLuhan, veio com a descoberta da eletricidade e a invenção do telégrafo. A nova era eletrônica causou e continua causando uma implosão na sociedade, fazendo com que os humanos voltem às suas antigas raízes orais. Esta última era da automação e da cibernetização nos remete de volta a um modo de vida mais participativo, integral, descentralizado e inclusivo. McLuhan declara que a eletricidade, com sua velocidade e constância, é o meio que criou a simultaneidade, é uma extensão do nosso sistema nervoso central, "inter-relacionando instantaneamente cada experiência humana” (1964, p. 358). Ele sugere que toda mídia é uma extensão de nós mesmos; a mídia impressa é uma extensão do olho, assim como a roda é uma extensão do pé.

Agora, mais do que nunca, estamos vendo a transformação de nossas sociedades no que McLuhan chamou de "vila global", e a era eletrônica da qual ele falou está a pleno vapor, remodelando sociedades e identidades no mundo todo. Para que a sociedade alfabetizada de hoje acompanhe a era da informação, a educação deve se libertar do currículo que é separado por disciplinas e "mudar totalmente para que haja uma inter-relação de conhecimento”, afirma McLuhan (p. 35). Ele pergunta (p. 230): 
Não pareceria natural e necessário que os jovens recebessem, ao menos, tanto treinamento de percepção neste mundo gráfico e fotográfico quanto eles recebem no tipográfico? De fato, eles precisam de mais treinamento em artes gráficas, pois a arte de elencar e organizar atores em anúncios é tanto complexa quanto forçosamente insidiosa.

Acrescentando-se perspectivas deterministas econômicas e tecnológicas ao determinismo tecnológico de McLuhan, Thomas Friedman (2005) argumenta que, na virada deste milênio, os humanos iniciaram a terceira grande etapa das mudanças globais. Ele escreve que a primeira grande era da globalização começou em 1492, quando Colombo abriu o comércio entre o novo e o velho mundos. Durante o que ele chama de Globalização 1.0, o imperialismo e a religião fizeram com que a integração global enfrentasse a força bruta, já que países colonizadores suprimiram o poder de povos explorados até mais ou menos 1800. A segunda era, a Globalização 2.0, compreendeu o período de aproximadamente 1800 a 2000 e envolveu empresas multinacionais, que expandiam seus mercados e forças de trabalho à medida que a industrialização remodelava o mundo. Essa segunda era beneficiou-se primeiramente da queda dos custos de transporte e, mais tarde, do declínio dos custos das telecomunicações, e foi marcada pelas invenções de novos dispositivos de hardware. Contudo, no século XXI, Friedman afirma que a Globalização 3.0 é movida por um software inovador e uma rede global de fibra óptica e declara que "o caráter único desta era é "o recém-descoberto poder dos individuos de colaborar e competir globalmente" (2005, p. 10).

Sua afirmação de que o mundo de hoje é menos hierárquico, com um campo de jogo mais plano do que nunca, é excessivamente ideológica e otimista. Friedman é muito pouco crítico de desigualdades e injustiças da globalização neoliberal (Klein, 2007). No entanto, sua afirmação de que "o mundo foi nivelado pela convergência de dez grandes eventos políticos, inovações e empresas” (p. 48) é altamente provocativa e ressalta muitas mudanças recentes na sociedade que estão tendo um impacto global. Não concordamos com sua conclusão utópica de que o mundo de hoje é nivelado e de que há mais igualdade de oportunidades, uma vez que um terço da população mundial ainda vive sem eletricidade. Mas a discussão de Friedman sobre as grandes forças que mudaram o mundo só nas duas últimas décadas deixa claro que o século XXI é um mundo diferente e continuará mudando, devido às influências de novas tecnologias de informação e comunicação e de sistemas 
Educação para a leitura crítica da mídia...

econômicos globais. Os exemplos que ele descreve de transformações na tecnologia, na sociedade e na economia demonstram fortes razôes para a necessidade de uma mudança na educação, especialmente nas práticas de alfabetização. Acreditamos que o tipo de mudança mais adequado a um mundo globalizado e perpetuamente transformado pela tecnologia incluiria múltiplas alfabetizações, entre as quais a alfabetização crítica da mídia é essencial, como argumentaremos a seguir.

A diversidade de idéias e pessoas está cada vez maior nos países, cidades e salas de aula, pois um volume de informação cada vez maior se disponibiliza e cada vez mais pessoas viajam e imigram no mundo. Ao mesmo tempo, há uma redução de diversidade, pois a colonização cultural e a homogeneização comercial se disseminam pelos mercados globais com a facilidade das novas tecnologias da informação e comunicação. Um exemplo da perda de diversidade pode ser visto no aviso da UNESCO de que "mais de $50 \%$ dos 6 mil idiomas do mundo estão ameaçados de extinção", com o desaparecimento de praticamente um a cada duas semanas. ${ }^{6}$ Joseph Lo Bianco (2000, p. 94) afirma que, "durante esta década e a próxima, haverá o maior declínio de diversidade lingüística em toda a história”. Ele atribui essas mudanças a um emergente sistema global que está sendo gerado por três forças principais: "A primeira é o fenômeno quase universal da desregulação de mercado; a segunda é a integração avançada dos mercados financeiros internacionais e a terceira é a força crítica facilitadora das comunicações instantâneas" (p. 93).

Um dos grandes temas comuns em análises das mudanças nas relações entre a mídia e a sociedade é um alto grau de convergência que está ocorrendo de várias maneiras (Considine, 2003; Gutiérrez, 2003; Luke, 2007, Jenkins, 2006). Henry Jenkins (2006) insiste que estamos vivendo hoje numa cultura de convergência, no sentido em que nossas práticas socioculturais estão mudando em função das influências da tecnologia, da economia e da convergência da velha e nova mídia. Ele explica (p. 15): "A convergência de mídia é mais do que simplesmente uma mudança tecnológica. A convergência altera a relação entre as tecnologias, indústrias, mercados, gêneros e audiências existentes”. Jenkins chama atenção para duas tendências grandes e freqüentemente contraditórias. Uma delas é a tendência das grandes empresas de mídia a ameaçar a democracia pela sua concentração de propriedade, dando 
a menos pessoas uma maior capacidade de empurrar e ampliar o seu conteúdo limitado para as massas. A outra é a tendência das novas tecnologias de mídia a ajudar as pessoas, em nível de participação, a puxar, criar e distribuir conteúdos de mídia muito mais diversificados, oferecendo, assim, novas oportunidades democráticas. Esse movimento dinâmico de "empurra-e-puxa" da mídia é um aspecto importante da convergência e, como Jenkins afirma (2006, p. 243),

Representa uma mudança de paradigma, a mudança de um conteúdo que é específico de um meio para um conteúdo que flua através de diversos canais de mídia. Esse movimento leva à crescente interdependência dos sistemas de comunicação, em direção de múltiplas formas de se acessar conteúdos de mídia, à existência de relações ainda mais complexas entre a mídia corporativa autoritária e a cultura participativa libertadora.

Essas mudanças na tecnologia e na sociedade estão modelando a forma como as pessoas pensam sobre a mídia e se relacionam com ela. Jenkins afirma que o maior problema para os educadores hoje não é a velha noção de uma divisão digital que separa as pessoas de acordo com o seu acesso às ferramentas de comunicação, uma vez que existe hoje um número nunca antes visto de pessoas que têm acesso a elas. $\mathrm{O}$ maior problema hoje é um vácuo de participação, ou seja, "acesso desigual às oportunidades, experiências, habilidades e conhecimento que irão preparar os jovens para a plena participação no mundo de amanhã " (Jenkins et al., 2007, p. 3). Jenkins escreve (2006, p. 259): "Precisamos reavaliar os objetivos da educação midiática, para que os jovens possam se ver como produtores culturais e participantes, e não simplesmente como consumidores, críticos ou não".

Considerando as mudanças em termos tecnológicos e sociais, Carmen Luke (2006) defende uma forma ampliada de alfabetização midiática devido a três níveis de convergência de mídia que crescem cada vez mais. Um desses níveis é a habilidade funcional de dispositivos de hardware de executar múltiplas tarefas, como um telefone celular que pode tirar e enviar imagens (fixas e em movimento), tocar música, enviar e receber mensagens de texto, carregar e baixar conteúdo on-line, usar jogos e até ser usado para se falar com as pessoas. Um segundo nível refere-se à convergência amplamente enfatizada pelas desregulações da propriedade de mídia e as diversas fusões e aquisições 
Educação para a leitura crítica da mídia...

de corporações multinacionais de mídia. A integração horizontal e vertical de empresas de mídia permite que menos corporações tenham a habilidade de controlar mais tipos diferentes de serviços e conteúdos (Bagdikian, 1997; McChesney, 2004). A habilidade das tecnologias de informação e comunicação de desempenhar mais funções e a integração de fornecedores de mídia estão criando o que Marsha Kinder (1991) chama de intertextualidade transmidia.

Segundo Luke, o terceiro nível de convergência de mídia é a conseqüência do primeiro e do segundo, produzindo o efeito de criar "uma sinergia muito mais sólida entre indústrias anteriormente distintas, entre conhecimento e informação, consumismo, cultura popular, entretenimento, comunicação e educação" (2006, p. 5). Enquanto a política, as notícias e o entretenimento convergem em novas formas de mídia, forma-se toda uma cultura de audiência. $\mathrm{O}$ espetáculo está se tornando um dos princípios organizadores da economia, do Estado, da sociedade e do dia-a-dia das pessoas (Kellner, 2003 e 2007). Para captar maiores audiências e ampliar o lucro e o poder, as indústrias de cultura agressivamente criam e promovem uma cultura de mídia sintetizada, centrada no espetáculo.

James Paul Gee (2000) sugere que as inovações tecnológicas e o "rápido capitalismo" global e hiper-competitivo estão criando um novo tipo de indivíduo que ele chama de "pessoa portfólio" (p. 43). Gee explica que a idéia de 'habilidade especial' "deixou de ter a conotação de especialidade 'disciplinar' ou acadêmica para abranger uma noção mais ampla, mais compatível com a nova visão do mundo capitalista” (p. 48). Ele escreve que esta orientação empresarial, muito semelhante à perspectiva de um mundo nivelado de Friedman, enfatiza

A eficiência na solução de problemas, produtividade, inovação, adaptação e sistemas distribuídos, não autoritários (...). No novo capitalismo, não importa muito aquilo que os indivíduos sabem isoladamente, mas o que eles sabem fazer colaborativamente, com outros indivíduos, para efetivamente acrescentar "valor" à empresa. (p. 49)

Um problema desta educação da pessoa portfólio é que ela se baseia numa noção cognitiva de trabalhadores do conhecimento, que têm a habilidade do "pensamento superior", mas não possuem a habilidade de pensar criticamente. Gee descreve "pensar criticamente" como a habilidade de "entender e criticar sistemas de poder e injustiça" (p. 62). A 
falta de habilidade para entender ou simpatizar com pessoas marginalizadas, pobres e oprimidas é um grande problema desta epistemologia do rápido capitalismo.

Outro problema do modelo que cria a pessoa portfólio é que ele favorece mais as crianças de posiçóes dominantes na sociedade (ou seja, brancas, do sexo masculino, de classe média ou alta), que têm acesso mais fácil a essa linguagem especializada e "escolar", baseada em suas experiências de vida e em seus privilégios. É muito mais fácil ligar a cultura doméstica ao domínio público da escola para alunos que foram expostos a valores da classe média branca, como a leitura de literatura infantil desde os primeiros anos de vida ou visitas a museus e galerias de arte. A comum abordagem da deficiência de pensamento, que muitos educadores internalizam, subestima os bens culturais que alunos pobres e pertencentes a minorias trazem para a escola e freqüentemente encara os recursos como problemas a superar (Valencia \& Solorzano, 2004). Gee escreve:

Nós raramente construímos a partir de suas experiências e seu conhecimento de vida e mundo, tão real e característico. Na verdade, no processo de serem expostos a domínios especializados, pede-se freqüentemente que neguem o valor de suas experiências de vida e em suas comunidades, em detrimento dos das crianças mais favorecidas. (2000, p. 66)

Para contrabalançar os problemas de desigualdade e falta de crítica social, Gee promove uma Carta de Direitos para todos os alunos, incluindo quatro princípios pedagógicos: práticas situadas, instrução aberta, estruturação crítica e práticas transformadoras. Ele escreve: "Estes princípios buscam produzir pessoas que possam atuar no novo capitalismo, mas de uma maneira muito mais meta-consciente e política do que as complexas formas de escolaridade neo-capitalistas" (p. 67). A prática situada pode ajudar na valoração dos diferentes tipos de capital cultural (Bourdieu, 1986) que os alunos trazem para a sala de aula, assim como as práticas experienciais centradas na criança permitem que os alunos descubram conexōes entre suas experiências de vida e a escola. Um aspecto importante desses princípios é uma consciência meta-cognitiva das interconexōes entre o pensamento, o conhecimento $\mathrm{e}$ as relaçōes de poder. A necessidade de instrução aberta e da estruturação crítica garante que os alunos se envolvam criticamente com textos para compreender as interconexôes e os sistemas de poder. 
O quarto princípio, da prática transformada, sugere que a educação deve envolver o fato de se atuar sobre o aprendizado e de se dar poder aos alunos para usar e transformar o conhecimento. Quando o quarto princípio de Gee, o da prática transformadora, se constrói sobre a estruturação crítica, então o objetivo de Jenkins de eliminar ou diminuir o vácuo de participação pode se tornar uma reconstrução da educação, promovendo a alfabetização crítica da mídia. Em um relatório financiado pela Fundação MacArthur (MacArthur Foundation), Jenkins e outros autores defendem a necessidade de se ensinar

(...) novas alfabetizações midiáticas: um conjunto de competências culturais e habilidades sociais de que os jovens necessitam na nova paisagem da mídia. A cultura participativa muda seu foco de alfabetização do nível de expressão individual para o de envolvimento comunitário. Quase todas as novas formas de alfabetização envolvem habilidades sociais desenvolvidas com colaboração e trabalho em rede. Essas habilidades se constroem sobre a base da alfabetização tradicional, as habilidades de pesquisa, habilidades técnicas e habilidades de análise crítica ensinadas em sala de aula. (Jenkins et al., 2007, p. 4)

\section{Abordagens à educação midiática}

Embora a educação midiática nos Estados Unidos esteja ainda na sua infância, já existe debate sobre por que e como colocá-la em prática (Hobbs, 1998). Dividimos o campo da pedagogia midiática em quatro abordagens gerais, para poder melhor explicar os elementos necessários da alfabetização crítica da mídia (Kellner, 1998; Kellner \& Share, 2005).

Uma das abordagens à educação midiática provém de um medo da mídia e visa a proteger ou inocular as pessoas contra os perigos da manipulação e dependência da mídia. Essa abordagem protecionista pressupóe as audiências da mídia como vítimas passivas e valoriza a tradicional cultura impressa sobre a cultura da mídia, como exemplificado por Neil Postman (1985) em Amusing ourselves to death (Divertindo-nos até morrer). Postman avisa que a TV detém o poder de controlar a educação porque ela domina a atenção, o tempo e os hábitos cognitivos dos jovens. Muitos ativistas dos dois lados do espectro político vêem a educação midiática como uma forma de sobrecarregar suas agendas, 
culpando a mídia. Alguns conservadores culpam a mídia por gravidezes em adolescentes e pela destruição de valores familiares, enquanto alguns da esquerda criticam a mídia pelo consumismo exacerbado e pela existência de crianças materialistas. Em uma pesquisa com professores de pré-escola e provedores de creches, Ellen Seiter (2002) detectou esse medo da mídia e esses traços da cultura popular como mais expressivos nas classes média e alta. Ela escreve: “a mídia é considerada mais poderosa pelos que trabalham e vivem em situações relativamente privilegiadas. Nos centros mais pobres, a mídia é vista como apenas um entre vários fatores, com um papel menos significante que o da pobreza, da ausência dos pais e da violência” (p. 59 e 60).

Se, por um lado, reconhecemos que a mídia contribui para a existência de muitos problemas sociais e às vezes até os causam, por outro lado, questionamos uma abordagem protecionista, pela sua tendência antimídia, que é demasiadamente simplista em relação à complexidade de nossas relações com a mídia e não leva em consideração o potencial que a pedagogia crítica e a produção de mídia alternativa oferecem para se dar poder às pessoas. Quando a compreensão dos efeitos da mídia é contextualizada em sua dinâmica sócio-histórica, as questões de poder e ideologia são extremamente úteis à educação midiática, para se explorar as inter-relações entre informação e poder (Ferguson, 2004). Os críticos dessa abordagem antimídia sugerem que ela irá fazer com que os alunos ou regurgitem respostas "politicamente corretas" à crítica da mídia ou rejeitem totalmente as idéias da alfabetização midiática (Buckingham, 1994). Alguns aspectos da abordagem protecionista podem ser úteis quando se referem aos processos naturalizantes de uma ideologia e as inter-relaçôes com a injustiça social, mas eles são profundamente falhos quando o fazem com ortodoxia dogmática e pedagogia não-democrática.

Uma segunda abordagem ao ensino sobre a mídia pode ser vista na educação em arte midiática, na qual os alunos são ensinados a valorizar as qualidades estéticas da mídia e das artes, enquanto usam sua criatividade para se expressar através da arte criativa e da mídia. Esses programas, em geral, podem ser encontrados em escolas, como aulas avulsas, ou fora da sala de aula, em programas de base comunitária ou extracurriculares. Se, por um lado, muitos desses programas são excelentes exemplos de alfabetização crítica da mídia, como descrevemos 
Educação para a leitura crítica da mídia...

mais adiante neste capítulo, por outro lado, temos preocupações com a abordagem da arte midiática quando favorece a auto-expressão individualista em detrimento da análise socialmente consciente e da produção de mídia alternativa. Muitos desses programas tendem a ensinar aos alunos habilidades técnicas para simplesmente reproduzir representações hegemônicas, sem provocar qualquer problematização, com pouca consciência de implicações ideológicas ou qualquer tipo de crítica social. Alguns teóricos de base feminista explicam que ter voz ativa é importante para pessoas que raramente têm permissão para falar por si próprias, mas sem análise crítica isso não é suficiente (Collins, 2004; Harding, 2004; Hartsock, 1997). A análise crítica que explora e expõe as estruturas de opressão é essencial, porque simplesmente ter voz ativa é algo que qualquer grupo racista ou sexista também pode reivindicar. Devem-se abrir espaços e criar oportunidades para que as pessoas de posições marginalizadas tenham a oportunidade de lutar coletivamente contra a opressão, externar suas inquietações e criar suas próprias representações.

Incorporar a produção de arte e mídia na educação é oferecer o potencial para tornar o aprendizado mais experimental, mais "mão-namassa”, criativo, expressivo e divertido. A educação em arte midiática pode trazer prazer e cultura popular para a educação corrente, tornando a escola, assim, mais motivadora e relevante para os alunos. Quando essa abordagem transcende as habilidades de produção técnica ou a apreciação relativista da arte e envereda pelos estudos culturais e pela pedagogia crítica, tratando de questôes de gênero, raça, classe, sexualidade e poder, ela tem potencial dramático para a alfabetização crítica da mídia e transformadora.

Uma terceira abordagem à educação midiática pode ser encontrada no movimento de alfabetização midiática nos EUA. Mesmo ainda relativamente pequeno, ${ }^{7}$ ele fez alguns avanços em importantes instituiçôes educacionais e estabeleceu duas associações nacionais nos Estados Unidos. De acordo com a definição de alfabetização midiática de uma das duas organizações nacionais de alfabetização midiática, a Alliance for a Media Literate America (Aliança para uma América Midiaticamente Alfabetizada), "considera-se que a alfabetização midiática consiste de uma série de competências comunicativas, incluindo as habilidades de acessar, analisar, avaliar e comunicar" ${ }^{8}$ Essa abordagem busca ampliar a noção de alfabetização, incluindo a cultura popular e múltiplas formas de mídia 
(música, vídeo, internet, anúncios etc.), e, ao mesmo tempo, ainda trabalhar dentro de uma tradição de alfabetização na forma impressa.

Mesmo concordando que há necessidade de refletir sobre essas idéias de ampliar a nossa compreensão de como nos comunicamos com mais do que simples palavras impressas, isso não é suficiente para fazer acontecer uma reconstrução democrática da educação e da sociedade. Robert Ferguson (1998) usa a metáfora de um iceberg para explicar a necessidade de análise crítica da mídia. Muitos educadores que trabalham sob uma estrutura de alfabetização midiática apolítica orientam seus alunos a apenas analisar a ponta óbvia e evidente do iceberg que eles vêem brotando de dentro d'água. Ferguson afirma que isso é um problema, porque "a vasta porção que não é imediatamente visível é a base intelectual, histórica e analítica, sem a qual a análise da mídia corre o risco de ficar superficial ou mecânica” (p. 2). O componente crítico da alfabetização midiática deve transformar a alfabetização em uma exploração do papel da linguagem e da comunicação para definir relações de poder e dominação, pois abaixo da superfície da água, naquele iceberg, vivem noções ideológicas profundamente embutidas, de supremacia branca, patriarcalismo capitalista, classismo, homofobia e outros mitos opressivos.

Muitos educadores da mídia que trabalham com essa abordagem expressam abertamente que acreditam que a educação pode e deve ser politicamente neutra e que seu trabalho é expor os alunos objetivamente aos conteúdos de mídia, sem pensar em questões de ideologia e poder. Henry Giroux (1997, p. 11) escreve: "A noção de que a teoria, os fatos e o questionamento podem ser determinados e usados objetivamente é aniquilada por um conjunto de valores de orientação política conservadora e mistificante". A rejeição da idéia de que a educação ou a informação podem ser neutras e livres de valores é essencial para o questionamento crítico que aborda a injustiça social e a desigualdade, através da pedagogia transformadora baseada na práxis (reflexão e ação). Giroux (2001, p. xxiv) defende que "educação não é treinamento, e que o aprendizado, em sua melhor forma, está diretamente relacionado a importantes questões de responsabilidade social e atitude política”.

A grande tendência atual do movimento de alfabetização midiática nos EUA, algo que está apenas começando a se desenvolver, é provavelmente a questão da sua base conservadora, que não abarca as dimensões políticas da educação, principalmente a alfabetização. Essa ambígua 
Educação para a leitura crítica da mídia...

instância apartidária, ao mesmo tempo em que ajuda na disseminação da educação midiática, disponibilizando algumas das idéias para mais alunos, também mina o potencial transformador da educação midiática de ser uma ferramenta poderosa para desafiar a opressão e fortalecer a democracia. O movimento de alfabetização midiática foi muito bem sucedido ao promover importantes conceitos de semiótica e intertextualidade, além de trazer a cultura popular para a educação pública. Contudo, sem a pedagogia crítica e os estudos culturais, a alfabetização midiática corre o risco de se tornar apenas mais um manual de idéias convencionais para melhorar a função de reprodução social da educação.

O tipo de alfabetização crítica da mídia que propomos inclui aspectos dos três modelos expostos, porém, enfocando a crítica ideológica e analisando a política de representação das dimensões cruciais de gênero, raça, classe e sexualidade na economia política e nas relaçóes sociais das importantes empresas de mídia. Esse modelo também amplia a noção de análise textual, incluindo questôes de contexto social, controle, resistência e prazer, promovendo a produção de mídia alternativa. Uma abordagem à alfabetização crítica da mídia também amplia a noção de alfabetização, incluindo a alfabetização pela informação, a alfabetização técnica, a alfabetização multimodal, e fazendo outras tentativas de ampliar conceitos de alfabetização por via impressa, incluindo diferentes ferramentas e modalidades de comunicação (Kellner, 1998). Além desses elementos, a alfabetização crítica da mídia proporciona uma compreensão da ideologia, do poder e da dominação, desafiando noções relativistas e apolíticas de grande parte dos que trabalham com educação midiática e orientando professores e alunos a compreender como o poder e a informação estão sempre relacionados. Essa abordagem abarca a noção de audiências ativas no processo de construção de significado, como uma luta cultural entre leituras dominantes, leituras de oposição ou leituras negociadas (Ang, 2002; Hall, 1980).

Dessa forma, a alfabetização crítica da mídia constitui uma crítica às tendências atuais de abordagem da alfabetização e um projeto político pela mudança social democrática. Isso envolve um questionamento crítico multiperspectivista da cultura popular e das indústrias populares, que trate de questôes de classe, raça, gênero, sexualidade e poder, além de promover a produção de mídia alternativa anti-hegemônica. A mídia e a tecnologia da informação e comunicação podem 
ser ferramentas de poder quando as pessoas geralmente mais marginalizadas ou mal representadas na mídia corrente recebem a oportunidade de utilizá-las para contar suas histórias e expressar suas inquietações. Para os membros do grupo dominante, a alfabetização crítica da mídia oferece uma oportunidade de envolvimento com as realidades sociais que a maior parte do mundo está experimentando. As novas tecnologias da comunicação são ferramentas poderosas que podem libertar ou dominar, manipular ou esclarecer, e é vital que os educadores ensinem seus alunos a usar e analisar criticamente esses tipos de mídia (Kellner, 2004).

As diferentes abordagens à educação midiática não são modelos pedagógicos rígidos e sim pontos de referência interpretativos, a partir dos quais os educadores podem estruturar seus objetivos, interesses e estratégias. A busca pela alfabetização crítica da mídia é importante para identificar os elementos e objetivos necessários para a boa pedagogia midiática. Alan Luke e Peter Freebody estão desenvolvendo uma compreensão dinâmica da alfabetização como prática social, na qual a competência crítica é uma das práticas necessárias. Essa estrutura da alfabetização como uma família de práticas, na qual é vital que se tenha múltiplas práticas e nenhuma sozinha é suficiente, combina bem com a nossa abordagem multiperspectivista à alfabetização crítica da mídia. Luke e Freebody (1999) escrevem que a efetiva alfabetização requer quatro papéis básicos que permitem que os aprendizes "decifrem o código (...) participem da compreensão e da estruturação (...) usem os textos funcionalmente (...) [e] analisem e transformem textos, agindo com o conhecimento de que um texto nunca é ideologicamente natural ou neutro". Essa abordagem normativa oferece a flexibilidade para que a alfabetização explore e envolva criticamente os alunos, na pedagogia que melhor funcionar para cada professor, em sua situação única com as diferentes necessidades e interesses sociais de seus alunos e da comunidade local.

Quando os educadores ensinam aos alunos a alfabetização crítica da mídia, muitas vezes começam com atividades de arte na mídia ou simplesmente decodificando textos de mídia, à moda do movimento estabelecido de alfabetização, discutindo como as audiências recebem as mensagens de mídia. Mas a alfabetização crítica da mídia também envolve alunos na exploração das profundezas do iceberg, com questôes críticas, para desafiar suposiçôes do "senso comum" e replanejar 
Educação para a leitura crítica da mídia...

a produção de mídia alternativa na arte com interpretações negociadas ou de oposição. O objetivo deve ser caminhar em direção à alfabetização crítica da mídia com a compreensão da alfabetização como um processo social que requer amplitude e profundidade, ao plantar as sementes e embasar os passos para a pedagogia transformadora.

Por exemplo, em seu curso sobre alfabetização crítica da mídia na Universidade da Califórnia (UCLA), Rhonda Hammer propóe que seus alunos trabalhem em grupos para criar seus vídeos anti-hegemônicos e/ou sites, explorando questôes que eles considerem pouco representadas ou mal representadas na mídia corrente (Hammer, 2006).9 Durante o curto período de dez semanas de curso, seus alunos produzem mídia alternativa que desafia as afirmaçóes de "senso comum" sobre uma grande variedade de questões referentes a gênero, etnia, sexualidade, política, poder e prazer. Por meio da dialética da teoria e prática, seus alunos criam mídia alternativa crítica que abarca os conceitos-chave da alfabetização crítica da mídia, adaptando-a à audiência, ao texto e ao contexto.

\section{Democracia radical}

A alfabetização crítica da mídia, na nossa concepção, está atrelada ao projeto de democracia radical e preocupa-se em desenvolver habilidades que intensifiquem a democratização e a participação cívica. Ela tem uma abordagem abrangente que envolve o ensino de habilidades críticas e de uso de mídia como instrumentos de comunicação social e mudança. As tecnologias da comunicação estão ficando cada vez mais acessíveis a jovens e cidadãos comuns e pode ser usada para promover a educação, a auto-expressão democrática e a justiça social. Existem as tecnologias que poderiam produzir o fim da democracia participativa, transformando a política em espetáculos da mídia, numa batalha das imagens, e fazendo dos espectadores consumidores passivos. Estas podem também ser usadas para estimular o debate democrático e a participação.

De fato, o ensino da alfabetização crítica da mídia deve ser um projeto participativo e colaborativo. Alunos e professores, assistindo a shows ou filmes juntos, podem promover discussões produtivas entre si (ou entre pais e filhos), buscando prioritariamente ouvir as opinióes 
dos alunos, produzindo várias interpretações de textos de mídia e ensinando princípios básicos da hermenêutica e da crítica. Os alunos e os jovens são geralmente mais preparados, conhecedores e imersos na cultura midiática do que seus professores e podem contribuir com seu processo educativo, compartilhando suas idéias e percepções e insights. Além da discussão crítica, do debate e da análise, os professores devem orientar seus alunos em um processo de questionamento que aprofunde sua exploração crítica de questões que afetem a eles e à sociedade. Como a cultura da mídia é parte essencial da identidade dos alunos e uma poderosa experiência cultural, os professores devem ter sensibilidade suficiente para criticar artefatos e percepções que são caras aos alunos, mas deve-se promover uma atmosfera de respeito crítico pela diferença e de questionamento sobre a natureza e os efeitos da cultura da mídia (Luke, 1997).

No entanto, um grande desafio no desenvolvimento da alfabetização crítica da mídia resulta do fato de que ela não é uma pedagogia, no sentido tradicional, com princípios firmemente estabelecidos, um cânone de textos e procedimentos de ensino testados e aprovados. Ela requer uma pedagogia democrática, que envolva professores partilhando o poder com os alunos e unindo-se a eles no processo de desvendar mitos, desafiar a hegemonia e buscar métodos para produzir sua própria mídia alternativa. A pedagogia crítica da mídia ainda é incipiente nos EUA; está apenas começando a produzir resultados e é mais aberta e experimental do que a pedagogia estabelecida, orientada por material impresso. ${ }^{10}$ Além disso, o material da cultura midiática é tão polimórfico, polivalente e polissêmico que requer sensibilidade para diferentes leituras, interpretações, percepções das complexas imagens, cenas, narrativas, significados e mensagens da cultura midiática. Esta última, à sua maneira, é tão complexa e desafiadora para se decifrar criticamente quanto a cultura bibliográfica.

O ensino da alfabetização crítica da mídia envolve a ocupação de um espaço acima da dicotomia do fanatismo e do censor. Pode-se ensinar como a cultura midiática fornece afirmações ou insights significativos sobre o mundo social, permitindo visões de gênero, raça e classe, ou complexas estruturas e práticas estéticas. Pode-se dar uma interpretação positiva ao seu modo de fornecer contribuições significativas para a educação. Porém, precisamos também indicar como a cultura 
Educação para a leitura crítica da mídia...

midiática pode avançar nas questões de sexismo, racismo, etnocentrismo, homofobia e outras formas de preconceito, além da distorção de informações, das ideologias problemáticas e dos valores questionáveis, promovendo uma abordagem dialética da mídia, de maneira apropriada.

Os conceitos centrais da alfabetização crítica da mídia são muito relevantes para a educação progressista e transformadora, quando ensinados por meio de uma abordagem democrática, com uma pedagogia crítica consonante com as idéias de educadores progressistas como John Dewey e Paulo Freire. Mais de um século atrás, Dewey defendia a educação para a democracia e enfatizava a leitura ativa, a experimentação e a resolução de problemas. A abordagem pragmática de Dewey relaciona a teoria à prática e faz com que os alunos, de maneira semelhante, relacionem a reflexão à ação (1916/1997). Utilizando uma pedagogia de problematização, Freire (1970) promove a consciência crítica que envolva a percepção de situações e problemas concretos, além da ação contra a opressão. A alternativa de problematização que Freire exercita requer a comunicação dialógica entre alunos e professores, que devem aprender uns com os outros e ensinar uns aos outros. Isso demanda a práxis, a reflexão crítica juntamente com a ação, para que se possa transformar a sociedade. Por essa razão, a educação midiática deve envolver a análise crítica e a produção crítica de mídia por parte do aluno.

Len Masterman (1994) declarou que o objetivo da educação midiática deve ser a autonomia critica, para que os alunos questionem criticamente a mídia mesmo sem a presença de seus professores. Robert Ferguson (2001) sugeriu que os alunos devem também aprender a solidariedade crítica, pois nunca se é verdadeiramente autônomo e as informações não existem isoladamente; elas estão sempre ligadas a relações hierárquicas de poder. Combinando os ideais da autonomia crítica aos da solidariedade crítica, propomos um modelo de democracia radical que promova a independência e a interdependência, mas fujam da dependência acrítica da mídia. Quando a mídia é vista como janelas simplesmente transparentes, as mensagens ficam neutralizadas, nós ficamos complacentes e a democracia deixa de ser representativa. Nossa dependência da mídia nos leva a renunciar à nossa participação ativa e nossos deveres cívicos de questionar, desafiar e corrigir injustiças sociais. A democracia radical depende de indivíduos que se preocupem 
uns com os outros, se envolvam em questóes sociais e trabalhem juntos para construir uma sociedade mais igualitária e menos opressiva.

Muitos programas extracurriculares como o Educational Video Center (EvC) - Centro Educacional de Vídeo, em Nova Iorque, e o REACH LA, em Los Angeles, oferecem excelentes exemplos de como a produção de mídia pode ser ensinada como um componente essencial da alfabetização crítica da mídia. Ambos os programas envolvem jovens moradores de áreas socialmente desfavorecidas do centro da cidade em atividades de produção de vídeo, nas quais exploram suas preocupações e criam sua mídia alternativa para desafiar as representações dominantes. O fundador e diretor executivo do EVC, Steven Goodman (2003, p. 3), escreve:

Esta abordagem à alfabetização crítica liga a análise à produção de mídia. $\mathrm{O}$ fato de aprender sobre o mundo está diretamente ligado à possibilidade de mudá-lo. O domínio da alfabetização, nesse sentido, não é somente uma questão de ter bom desempenho em testes padronizados; é um pré-requisito para a auto-representação e a cidadania autônoma.

A produção de mídia no REACH LA é mais do que apenas o ensino de habilidades isoladas; é parte de um programa estruturado com base em práticas pedagógicas que são vitais para personalizar e politizar os jovens e suas mensagens. A combinação das habilidades analíticas para desconstruir a mídia corrente com as habilidades artísticas e técnicas para construir a mídia alternativa e anti-hegemônica se torna um processo natural. Nos programas de Atividade Informática e de Atividade em Artes Digitais, os alunos aprendem sobre produção de vídeo, animação, artes digitais, criação e manutenção de web sites, além das habilidades necessárias para produzir uma revista anual para adolescentes chamada REACH for Me. Essas habilidades técnicas incorporam sua poesia, ilustrações e contos em campanhas de serviço público, com o objetivo maior de produzir mudanças em suas sociedades. Coerentemente com a pedagogia crítica, os alunos deixam de ser objetos de pesquisas e representações de mídia dos outros para se tornarem sujeitos com o poder de contar suas próprias histórias e coletivamente desafiar mitos dominantes e opressivos. Goodman (op. cit., p. 103) insiste que

(...) essas possibilidades só podem efetivamente se tornar realidades se os princípios norteadores dos programas forem baseados em um modelo que 
dê poder aos jovens. Isto é, para se trabalhar com a alfabetização crítica dos jovens, é necessário que os programas os valorizem e envolvam como participantes ativos na solução de problemas comunitários e como parceiros totais em seu próprio aprendizado e crescimento.

O REACH LA adota uma filosofia freiriana de problematização, ajudando os alunos a focar questóes que sejam problemáticas para eles, como HIV/AIDS, homofobia e racismo. O EVC tem um foco diferente, mas uma abordagem semelhante, como Goodman (p. 3) explica:

(...) além das inúmeras "habilidades de vida" que são tipicamente oferecidas aos jovens de risco, eles precisam estar envolvidos no estudo dos empecilhos sistêmicos que há no seu caminho, como a brutalidade policial, a desigualdade de recursos educacionais, más condições habitacionais e outros, e precisam saber que tipo de ação coletiva eles podem ter para remover esses empecilhos.

Foi sobre esses tipos de conexões do mundo real que Dewey escreveu há quase um século. Esse é o caminho para fazer com que a educação seja significativa para os alunos e para dar-lhes poder para serem participantes ativos, necessários à democracia radical.

\section{Conclusão}

A alfabetização precisa de mudanças e a educação midiática deve acontecer de cima para baixo e de baixo para cima. A alfabetização deve ser reestruturada para ampliar a definição de um texto, incluindo novas formas de comunicação e cultura popular. Ela deve intensificar os nossos processos crítico-analíticos e explorar a recepção da audiência, para que se aprenda a ler e criar criticamente textos de mídia e buscar justiça social, além de compreender os contextos políticos, econômicos, históricos e sociais em que todas as mensagens são escritas e lidas.

Os estudos culturais e a pedagogia crítica oferecem a base teórica para informar a prática que pode transformar a educação e a sociedade. Para conseguir avanços na educação midiática com base na alfabetização crítica da mídia, precisamos nos unir para angariar mais fundos para a educação, especialmente onde há maior necessidade, em cidades do interior. Precisamos desafiar a falsa sabedoria do pensamento dos testes de alto risco financeiro e o pensamento deficitário. Precisamos também treinar professores na pedagogia crítica e dar-lhes poder 
para usar sua criatividade mais do que o prescrito no currículo. Além disso, precisamos de conferências e educação para professores, com continuado aperfeiçoamento profissional que inclua estudos culturais, pedagogia crítica e aplicações práticas para saber como envolver os alunos com conceitos de alfabetização crítica.

Recomendamos que se instituam programas de educação midiática da pré-escola à universidade e que a conexão entre a alfabetização midiática e a produção se torne uma prática regular. Os padróes para os programas de educação midiática devem incluir a crítica às maneiras em que a mídia reproduz o racismo, o sexismo, a homofobia e outros preconceitos, e também estimular alunos a encontrar sua própria voz ao criticar a cultura midiática e produzir representaçôes alternativas. A educação midiática deve ser relacionada à educação para a democracia, na qual se estimula os alunos a serem participantes informados e letrados midiáticos em suas sociedades. Além disso, a alfabetização midiática deve ser relacionada à alfabetização pela informação, à alfabetização tecnológica, às artes e às ciências sociais. A alfabetização crítica da mídia deve ser um fio comum que passe por todas as áreas curriculares, uma vez que se refere à comunicação e à sociedade.

Atualmente, a política de alfabetização midiática nos EUA está em seus anos de formação e fez poucos avanços durante a era Bush-Cheney. Os desafios políticos incluem a superação da hegemonia conservadora e neoliberal e a criação de alternativas democráticas e progressistas. Subvenções federais e estaduais para projetos experimentais em alfabetização midiática podem ser extremamente benéficas e devem ser pleiteadas pelos educadores. ${ }^{11}$ Conferências nacionais e estaduais, cujo tema seja especificamente o ensino da alfabetização crítica da mídia, podem ser excelentes oportunidades de reuniāo e trabalho em conjunto para educadores e responsáveis por estabelecer novas políticas, ao compartilharem idéias e construírem um movimento. Grupos de pais devem fornecer recursos e discussões aos seus membros, para abordar as preocupações que têm com a mídia e ajudá-los a praticar a alfabetização crítica da mídia em casa. Organizações de pais devem também usar seu poder coletivo para interferir no currículo escolar e pressionar o Congresso a favor da educação progressista.

A tarefa de educadores e pesquisadores é a de envolver-se em um novo tipo de alfabetização que funcione, desde a pré-escola até a 
Educação para a leitura crítica da mídia...

educação superior, e incorpore novas tecnologias de informação e comunicação, a mídia e a cultura popular à pedagogia crítica. Esse trabalho deve desafiar as ideologias dominantes e dar poder aos jovens para desvendar os mitos, criando suas próprias representaçóes alternativas, que lhes levem a ter voz ativa e a lutar por justiça social. O objetivo deste projeto é ajudar os alunos a se tornarem cidadãos socialmente ativos e, ao mesmo tempo, transformar a sociedade em uma democracia menos opressiva e mais igualitária.

\section{Recebido em junho de 2008 e aprovado em julho de 2008.}

\section{Notas}

1. Mesmo considerando-se que todas as pessoas nascidas neste milênio já existissem desde a invenção da internet, dos telefones celulares e da televisão, isso não significa que todos tenham acesso a essa tecnologia. Como aproximadamente um terço (cerca de dois bilhôes) da população mundial ainda vive sem eletricidade, é importante lembrar que bilhões de pessoas estão sendo excluídas da chamada revolução tecnológica.

2. O Departamento de Censo dos EuA relata que $98,2 \%$ de todos os lares americanos tinham pelo menos um aparelho de televisão em 2001. Estatísticas disponíveis on-line: http:// www.census.gov/Press-Release/www/releases/archives/facts_for_features/001702.html

3. Essas informações são baseadas em entrevistas telefônicas aleatórias em 2003, com 1.065 pais de crianças entre 6 meses e 6 anos de idade. "Mídia na tela" refere-se a assistir à TV, assistir a vídeos/DVDs, usar um computador e jogar videogames. Essa pesquisa foi relatada no estudo De zero a seis, da Fundação da Família Kaiser (Kaiser Family Foundation).

4. O número de horas em contado com mídia é baseado em questionários de uma amostra de 2004, com 2.032 alunos com idades de 8 a 18, além de 694 diários de uso de mídia, como relatado no estudo Geração $M$, da Fundação da Família Kaiser. A quantidade de seis horas e meia por dia inclui um quarto do tempo executando várias tarefas, com vários tipos diferentes de mídia ao mesmo tempo; portanto, aumentando a exposição à mídia para uma média de oito horas e meia por dia.

5. Oito Conceitos Principais do Ministério da Educação em Ontario (Canadá), Questões Indicativas do Instituto Britânico de Filmes (British Film Institute), os Cinco Conceitos Centrais do Centro para Alfabetização Midiática (The Center for Media Literacy) (Masterman, 2001) etc.

6. A citação foi encontrada no site oficial da UNESCO e obtida em 23 de outubro de 2006, a partir de: <http://portal.unesco.org/culture/en/ev.php-URL_ID=8270\&URL_DO=DO_ TOPIC\&URL_SECTION=201.html>

7. Vide Kellner \& Share, 2005.

8. Esta parte da definição da Aliança para uma América Midiaticamente Letrada (The Alliance for a Media Literate America) está disponível on-line em: <http://www.amlainfo.org/ medialit/index.php>

Educ. Soc., Campinas, vol. 29, n. 104 - Especial, p. 687-715, out. 2008

Disponível em <http://www.cedes.unicamp.br> 
9. O site do curso de Hammer pode ser visto em: <http://www.sscnet.ucla.edu/05F/ womencm $178-1 />$

10. Espalhados pelos EUA, há um número relativamente pequeno de educadores em escolas e fora delas, ensinando alfabetização crítica da mídia a alunos sortudos, da pré-escola à universidade. Estes educadores freqüentemente lutam contra muitos obstáculos, tendo que criar seus próprios materiais e trabalhar relativamente isolados. Embora o apoio à educação midiática esteja crescendo a partir das duas organizações nacionais de alfabetização midiática, a Aliança para uma América Midiaticamente Letrada (The Alliance for a Media Literate America) e a Coalizão de Ação para a Educação Midiática (The Action Coalition for Media Education), e de outras associações de professores, como o Conselho Nacional de Professores de Inglês (National Council of Teachers of English) e o Conselho Nacional para os Estudos Sociais (National Council for the Social Studies), a alfabetização midiática ainda está relegada a um segundo plano, com pouco reconhecimento e ainda menos apoio financeiro. Para obter um rico dossiê de textos sobre educação midiática e recursos para o seu ensino, vide Stack e Boler (2007, p. 6-16).

11. Vide a tese de doutorado de Jeff Share (2006).

\section{Referências}

ANG, I. On the politics of empirical audience research. In: DurHAM, M.G.; Kellner, D.M. (Ed.). Media and cultural studies key works. Malden: Blackwell, 2002. p. 177-197.

BAGDIKIAN, B.H. The media monopoly. Boston: Beacon, 1997.

BOURDIEU, P. The forms of capital. In: Richardson, J. (Ed.). Handbook of theory and research for the Sociology of Education. New York: Greenwood, 1986. p. 241-258.

BUCKINGHAM, D. Children talking television: the making of television literacy. London: Falmer, 1994.

BUCKINGHAM, D. Media education: literacy, learning and contemporary culture. Cambridge, Mass.: Polity, 2003.

CARRINGTON, V. New textual landscapes, information and early literacy. In: Marsh, J. (Ed.). Popular culture, new media and digital literacy in early childhood. London: Routledge; Falmer, 2005. p. $13-17$.

CASTELlS, M. The power of identity. In: Castells, M. The information age: economy, society and culture. 2. ed. Malden: Blackwell, 2004. v.2. 
Educação para a leitura crítica da mídia...

COLLINS, P.H. Learning from the outsider with: the sociological significance of black feminist thought. In: Harding, S. (Ed.). Feminist standpoint theory reader: intellectual and political controversies. New York: Routledge, 2004. p. 103-126.

CONSIDINE, D. Weapons of mass destruction?: media literacy, social studies and citizenship. In: DunCA, B.; TyNER, K. Visions/revisions: moving forward with media education. Madison: National Telemedia Council, 2003. p. 24-45.

DEWEY, J. Democracy and education. New York: The Free, 1916/ 1997.

FERGUSON, R. Representing 'race': ideology, identity and the media. New York: Oxford University, 1998.

FERGUSON, R. Media education and the development of critical solidarity. Media Education Journal, Moscow, n. 30, p. 37-43, 2001.

FERGUSON, R. The media in question. London: Arnold, 2004.

FREIRE, P. Pedagogy of the oppressed. New York: Seabury, 1970.

FRIEDMAN, T.L. The world is flat: a brief history of the twenty-first century. New York: Farrar, Straus \& Giroux, 2005.

GEE, J.P. New people in new worlds: networks, the new capitalism and schools. In: Cope, B.; Kalantzis, M. Multiliteracies: literacy, learning and the design of social futures. Melbourne: Macmillan, 2000. p. 43-68.

GIROUX, H. Pedagogy of the politics of hope: theory, culture, and schooling. Boulder: Westview, 1997.

GIROUX, H. Theory and resistance in education: towards a pedagogy for the opposition. Westport: Bergin \& Garvey, 2001.

GOODMAN, S. Teaching youth media: a critical guide to literacy, video production, and social change. New York: Teachers College, 2003.

GUTIÉRREZ MARTÍN, A. Multimedia authoring as a fundamental principle of literacy and teacher training in the information age. 
In: Duncan, B.; Tyner, K. (Ed.). Visions/revisions: moving forward with media education. Madison: National Telemedia Council, 2003. p. 12-22.

HALL, S. Encoding/decoding. In: Hall, S. et al. (Ed.). Culture, media, language. London: Hutchinson, 1980. p. 128-138.

HAMMER, R. Teaching critical media literacies: theory, praxis and empowerment. InterActions: UCLA Journal of Education and Information Studies, Los Angeles, v. 2, n. 1, 2006. Disponível em: <http:// repositories.cdlib.org/gseis/interactions/vol2/iss1/art7/>

HARDING, S. Rethinking standpoint epistemology: what is "strong objectivity"? In: HARDING, S. (Ed.). Feminist standpoint theory reader: intellectual and political controversies. New York: Routledge, 2004. p. $127-140$.

HARTSOCK, N. The feminist standpoint: developing the ground for a specifically feminist historical materialism. In: KemP, S.; SQUIRES, J. (Ed.). Feminisms. New York: Oxford University, 1997. p. 152-160.

HOBBS, R. The seven great debates in the media literacy movement. Journal of Communication, New York, v. 48, n. 1, p. 16-32, 1998.

HOUSTON, B. Viewing television: the metapsychology of endless consumption. Quarterly: Review of Film Studies, v. 9, n. 3, p. 183195, 1984.

JENKINS, H. Convergence culture: where old and new media collide. New York: New York University, 2006.

JENKINS, H. et al. Confronting the challenges of participatory culture: media education for the $21^{\text {st }}$ century. Chicago, MacArthur Foundation, 2006. Disponível em: <http://www.projectnml.org/files/working/NMLWhitePaper.pdf> Acesso em: 01 dez. 2007.

KELLNER, D. Media culture: cultural studies, identity and politics between the modern and the postmodern. London: Routledge, 1995.

KELLNER, D. Multiple literacies and critical pedagogy in a multicultural society. Educational Theory, Urbana, v. 48, n. 1, p. 103-122, 1998. 
Educação para a leitura crítica da mídia...

KELLNER, D. Media spectacle. London: Routledge, 2003.

KELLNER, D. Technological transformation, multiple literacies and the re-visioning of education. E-Learning, v. 1, n. 1, p. 9 37, 2004.

KELLNER, D. Guys and guns Amok: domestic terrorism and school shootings from the Oklahoma City bombings to the Virginia Tech massacre. Boulder: Paradigm, 2007.

KELLNER, D.; SHARE, J. Toward critical media literacy: core concepts, debates, organizations and policy. Discourse: studies in the cultural politics of education, Queensland, v. 26, n. 3, p. 369-386, 2005.

KINDER, M. Playing with power in movies, television, and video games. Berkeley: University of California, 1991.

KLEIN, N. The shock doctrine: the rise of disaster capitalism. New York: Metropolitan Books, 2007.

LO BIANCO, J. Multiliteracies and multilingualism. In: Cope, B.; Kalantzis, M. Multiliteracies: literacy, learning and the design of social futures. Melbourne: Macmillan, 2000. p. 92-105.

LUKE, C. Media literacy and cultural studies. In: MuspratT, S.; LuKE, A.; Freebody, P. (Ed.). Constructing critical literacies: teaching and learning textual practice. Cresskill, NJ: Hampton, 1997. p. 19-49.

LUKE, A.; FREEBODY, P. Further notes on the four resources model. Reading Online. 1999. Disponível em: <http://www.readingonline.org/ research/lukefreebody.html> Acesso em: 12 fev. 2006.

LUKE, C. As seen on TV or was that my phone?: new media literacy. Policy Futures in Education, Queensland, v. 5, n. 1, p. 50-58, 2007.

MCCHESNEY, R. The problem of the media: U.S. communication politics in the $21^{\text {st }}$ century. New York: Monthly Review, 2004.

MCLUHAN, M. Understanding media: extensions of man. Cambridge, Mass.: MIT, 1964.

MASTERMAN, L. A rationale for media education (first part). In: Masterman, L.; Mariet, F. Media education in 1990's' Europe. Strasbourg: Council of Europe, 1994. p. 5-87. 
MASTERMAN, L. Teaching the media. New York: Routledge, 2001. MODLESKI, T. Loving with a vengeance: mass produced fantasies for women. New York: Routledge, 1982.

POSTMAN, N. Amusing ourselves to death: public discourse in the age of show business. New York: Penguin Books, 1985.

RIDEOUT, V.; ROBERTS, D.F.; FOEHR, U.G. Generation M: media in the Lives of 8-18 year-olds. Washington, DC: Kaiser Family Foundation, 2005. Disponível em: <http://www.kff.org/entmedia/ entmedia030905pkg.cfm> Acesso em: 14 maio 2005.

RIDEOUT, V.J.; VANDEWATER, E.A.; WARTELLA, E.A. Zero to six: electronic media in the lives of infants, toddlers and preschoolers. Washington, DC: Kaiser Family Foundation, 2003.

SEITER, E. Television and new media audiences. New York: Oxford University, 2002.

SHARE, J. Critical media literacy is elementary: a case study of teachers' ideas and experiences with media education and young children. 2006. Tese (Doutorado) - Universidade da Califórnia, Los Angeles.

STACK, M. AND BOLER, M. Media and policy in education. Policy Futures in Education, Queensland, v. 5, n. 1, p. 6-16, 2007.

VALENCIA, R.; SOLORZANO, D. Today's deficit thinking about the education of minority students. In: Santa Ana, O. (Ed.). Tongue tied: the lives of multilingual children in public education. New York: Rowman and Littlefield, 2004. 